\title{
Title: A trimeric human angiotensin-converting enzyme 2 as an anti- SARS-CoV-2 agent in vitro
}

Authors: Tianshu Xiao ${ }^{1,2}$, Jianming Lü ${ }^{3 \#}$, Jun Zhang ${ }^{1,2 \#}$, Rebecca I. Johnson ${ }^{4 \&}$, Lindsay G.A. McKay ${ }^{4 \&}$, Nadia Storm ${ }^{4 \&}$, Christy L. Lavine ${ }^{5}$, Hanqin Peng ${ }^{1}$, Yongfei Cai ${ }^{1,2}$, Sophia Rits-Volloch ${ }^{1}$, Shen Lu ${ }^{3}$, Brian D. Quinlan ${ }^{6}$, Michael Farzan ${ }^{6}$, Michael S. Seaman ${ }^{5}$, Anthony Griffiths ${ }^{4}$, Bing Chen ${ }^{1,2^{*}}$

Affiliations: ${ }^{1}$ Division of Molecular Medicine, Boston Children's Hospital, and ${ }^{2}$ Department of Pediatrics, Harvard Medical School, 3 Blackfan Street, Boston, MA 02115

${ }^{3}$ Codex BioSolutions, Inc., 401 Professional Drive, Gaithersburg, MD 20879,

${ }^{4}$ Department of Microbiology, Boston University School of Medicine and National Emerging Infectious Diseases Laboratories, 620 Albany Street, Boston, MA 02118

${ }^{5}$ Center for Virology and Vaccine Research, Beth Israel Deaconess Medical Center, 330 Brookline Avenue, Boston, MA 02115

${ }^{6}$ Department of Immunology and Microbiology, Scripps Research Institute, 130 Scripps Way, Jupiter, FL 33458

${ }^{\#}$ and ${ }^{\&}$ These authors contributed equally to this work.

*Correspondence to: Bing Chen, phone: 617-355-4625, FAX: 617-730-1967, Email: bchen@crystal.harvard.edu. 


\begin{abstract}
Effective intervention strategies are urgently needed to control the COVID-19 pandemic. Human angiotensin-converting enzyme 2 (ACE2) is a carboxypeptidase that forms a dimer and serves as the cellular receptor for SARS-CoV-2. It is also a key negative regulator of the renin-angiotensin system (RAS), conserved in mammals, which modulates vascular functions. We report here the properties of a trimeric ACE2 variant, created by a structure-based approach, with binding affinity of $\sim 60 \mathrm{pM}$ for the spike (S) protein of SARS-CoV-2, while preserving the wildtype peptidase activity as well as the ability to block activation of angiotensin II receptor type 1 in the RAS. Moreover, the engineered ACE2 potently inhibits infection of SARS-CoV-2 in cell culture. These results suggest that engineered, trimeric ACE2 may be a promising anti-SARS-CoV-2 agent for treating COVID-19.
\end{abstract}




\section{Introduction}

The current COVID-19 pandemic, caused by severe acute respiratory syndrome coronavirus 2 (SARS-CoV-2), has infected more than 29 million people worldwide, leading to over 900 thousand deaths, with devastating socio-economic impacts. Effective intervention strategies are urgently needed to control the pandemic.

Since the outbreak of the virus, several therapeutic approaches have been evaluated in the hope of providing a viable treatment for COVID-19. First, convalescent sera from individuals recovered from the infection were used with encouraging results ${ }^{1-3}$, but also some drawbacks (e.g., batch variations, possible blood-borne pathogens and blood-type matching). Second, patient-derived, potently neutralizing monoclonal antibodies have been isolated, which could provide a more powerful passive immunotherapy than convalescent sera $^{4-7}$. Third, structure-guided design of peptide-based viral entry inhibitors has yielded promising leads in in vitro assays ${ }^{8,9}$; their efficacy requires further clinical evaluation. Fourth, known drugs or drug candidates, including remdesivir, favipiravir and ribavirin (viral RNA polymerase inhibitors); lopinavir and ritonavir (viral protease inhibitors); as well as hydroxychloroquine, corticosteroids and interferons (with more complicated antiviral mechanisms), have been repurposed as COVID-19 therapuetics ${ }^{10,11}$. Among them, remdesivir has received Emergency Use Authorizations (EUA) from the U.S. Food and Drug Administration (FDA), while hydroxychloroquine has been shown to be ineffective ${ }^{12}$. Finally, many new therapeutic candidates are in various stages of development $\quad\left(\operatorname{ref}^{13,14} ; \quad\right.$ https://www.bio.org/policy/human-health/vaccinesbiodefense/coronavirus/pipeline-tracker). While the infection resolves on its own in most asymptomatic and mild cases over time, COVID-19 in severe cases appears to progress in two phases - initial active viral replication in the respiratory system and subsequent excessive immune responses leading to multiple organ failure and possible death ${ }^{15}$. Thus, antivirals alone may be insufficient to change the course of disease progression for the population that needs intervention the most if administrated too late.

Human angiotensin-converting enzyme 2 (ACE2) is the cellular receptor for SARS-CoV2 and binds the receptor binding domain (RBD) of the spike (S) protein of the virus to 
promote viral entry into the host cells and initiate infection ${ }^{16,17}$. It is a type I membrane glycoprotein containing an extracellular ectodomain that has metallopeptidase activity. Its neck domain near the transmembrane anchor mediates dimerization ${ }^{18}$. ACE2 is also a key negative regulator of the renin-angiotensin system (RAS) - a major hormone system, conserved in mammals and some other vertebrate animals, for modulating vascular function $^{19,20}$. The RAS controls extracellular fluid volume and blood pressure homeostasis by regulating the levels of renin and angiotensins in the circulation. Renin cleaves angiotensinogen to release angiotensin I (Ang I), which can be further processed by angiotensin-converting enzyme (ACE) into angiotensin II (Ang II) - a vasoconstrictive peptide that raises blood pressure and increases the extracellular fluid volume in the body by activating the angiotensin II receptors, including angiotensin II receptor type I $(\mathrm{AT} 1 \mathrm{R})^{21}$. ACE2 primarily converts Ang II to angiotensin-(1-7) (Ang 1-7), which is a vasodilator, thereby counter-balancing the effect of ACE/Ang II and playing critical roles in preventing hypertension and tissue damages ${ }^{22}$.

The protective roles of ACE2 in acute respiratory distress syndrome (ARDS) and acute lung injury (ALI) have been demonstrated in animal models ${ }^{23-25}$. A recombinant soluble human ACE2 (rhACE2) was recently reported to block SARS-CoV-2 infection in cell culture and human organoids $^{26}$, prompting a phase 2 clinical trial for use of rhACE2 as a treatment for COVID-19 patients (NCT04335136). Thus, administration of exogenous ACE2 may be a promising therapeutic strategy for treating COVID-19, because it could not only block viral spread but also modulate the RAS to prevent organ injury. We therefore set out to design a series of ACE2 variants to enhance their binding affinity for SARS-CoV-2 S protein and their potency in blocking SARS-CoV-2 infection.

\section{Results}

\section{Structures of soluble ACE2 in complex with SARS-CoV-2 S protein trimer}

To facilitate design of ACE2-based viral fusion inhibitors, we first determined, by cryoEM, the structures of a monomeric soluble ACE2 (residue 18-615) in complex with a stabilized soluble SARS-CoV-2 S protein trimer (Fig. S1; ref $^{27}$ ). We prepared the complex by mixing the two proteins because the monomeric ACE2 dissociates from $\mathrm{S}$ 
trimer very rapidly ${ }^{28}$. After 3D classification (Fig. S2 and S3), we found four distinct classes that represent ACE2-free S trimer in the one-RBD-up conformation, one ACE2 bound S trimer, two ACE2 bound S trimer, and three ACE2 bound S trimer, respectively (Fig. 1). Consistent with previous findings with ACE2 binding to SARS-CoV S protein as well as a recent SARS-CoV-2 study ${ }^{29}$, ACE2 interacts with the RBD in its up conformation. While the NTD (N-terminal domain) of S1 shifts outwards slightly, the S2 portion remains largely unchanged upon ACE2 binding, even when compared to our recently published structure of the full-length $\mathrm{S}$ protein in the closed prefusion conformation $^{28}$. The structure of the complex with three ACE2 bound is not symmetrical, as the distances between the C-termini of the three ACE2s (residue Tyr613) are 107 $\AA$, $109 \AA$ and $120 \AA$, respectively (Fig. S4). This distance in the complex with two ACE2s bound is $110 \AA$. These observations suggest that there is a modest degree of freedom for the up conformation of RBD when ACE2 is bound. All the substrate binding sites of the bound ACE2s face away from the threefold axis of the S trimer (Fig. S4), incompatible with the structure of the full length ACE2 dimer in complex with the amino acid transporter $\mathrm{B}^{0} \mathrm{AT} 1$, in which the two active sites of the two protomers are facing each other $^{18}$. If the $\mathrm{B}^{0} \mathrm{AT} 1$-bound ACE2 dimer is indeed the form recognized by SARS-CoV2 , it appears that only one ACE2 protomer in the dimer can bind one RBD in an S trimer unless there are unexpectedly large structural rearrangements in either ACE2 or S.

\section{Design of ACE2 variants to enhance its binding affinity to SARS-CoV-2 S trimer}

Measurements of the binding kinetics of soluble monomeric ACE2 (ACE2 615 ; Fig. 2) to the SARS-CoV-2 S trimer shows a relatively fast dissociation rate ${ }^{28}$, limiting its ability to compete with the membrane bound ACE2 on the surface of a target cell. We therefore sought to enhance the effective affinity by creating a trimeric form of soluble ACE2. We fused a trimerization foldon tag, derived from bacteriophage $\mathrm{T} 4$ fibritin $^{30}$, to the Cterminal end of the ACE2 peptidase domain (residue 615) through a 11-residue flexible linker, a construct we refer to as ACE2 615 -foldon (Fig. 2). We have also created another version (ACE2 615 -LL-foldon) with a slightly longer linker (LL) with 13 residues between ACE2 and the foldon tag to assess its impact on binding. To further strengthen the interaction between $\mathrm{ACE} 2$ and the RBD, we introduced mutations guided by high- 
resolution structures (Fig. S5; ref $^{31}$ ), at three different positions in the ACE2-RBD interface - T27, H34 and K353, respectively. Substitution with a bulky hydrophobic residue at each of these sites may enhance hydrophobic interactions between the two proteins and slow the dissociation (Fig. S5). We designed five mutants, T27Y, T27W, $\mathrm{H} 34 \mathrm{~W}, \mathrm{~K} 353 \mathrm{Y}$ and $\mathrm{K} 353 \mathrm{~W}$, in the ACE2 615 -foldon background. Finally, for comparison, we also include two versions of dimeric forms, ACE2 $\mathrm{m}_{615}-\mathrm{Fc}$ and ACE2 $740-\mathrm{Fc}$, both fused to an Fc domain of an immunoglobulin G (Fig. 2A). ACE2m615-Fc contains H374N and H378N mutations at its peptidase active site and ACE2740-Fc includes the neck domain that mediates dimerization in the full length ACE2 ${ }^{18}$.

To produce the soluble recombinant ACE2 and its variants, we transfected HEK293 cells with the expression constructs of the monomeric and trimeric forms containing a $\mathrm{C}$ terminal his tag and purified the proteins by Ni-NTA and gel filtration chromatography. The two dimeric forms were purified by protein $G$ resin followed by gel filtration chromatography. While the monomeric and dimeric forms of soluble ACE2 were mostly secreted into cell medium, as judged by western blot, the trimeric ACE2 615 -foldon and its mutants were largely retained inside the cells. We therefore purified the secreted monomer and dimers from the cell supernatants and all the trimers from the cell lysates. Most proteins eluted from a size-exclusion column as a major symmetrical peak, regardless their secretion status (Fig. S6). The ACE2 ${ }_{740}-\mathrm{Fc}$ protein containing the dimerizing neck domain appeared to aggregate substantially more than other constructs. The ACE2 615 -foldon K353W mutant aggregated completely, and we therefore did not pursue this construct any further. Only the fractions from the major peak for each construct were pooled and used for subsequent analyses. We also compared the secreted ACE2 615 -foldon with the form purified from the cells and their biochemical properties were almost identical (Fig. S7).

\section{Binding to SARS-CoV-2 soluble S trimer}

We next measured binding of these recombinant ACE2 constructs to the stabilized soluble $\mathrm{S}$ trimer by bio-layer interferometry (BLI). As shown in Figs. 2B and S8, the monomeric $\mathrm{ACE} 2{ }_{615}$ had a fast dissociation rate and a $\mathrm{K}_{\mathrm{D}}$ of $77 \mathrm{nM}$, consistent with the 
measurement that we reported recently using surface plasmon resonance $\left(\mathrm{SPR} ; \mathrm{ref}^{28}\right)$. The dimeric ACE2 $\mathrm{m}_{615}$-FC bound slightly more tightly $\left(\mathrm{K}_{\mathrm{D}} \sim 22 \mathrm{nM}\right)$. The dimeric ACE2 ${ }_{740}-\mathrm{Fc}$ also bound more strongly than did the monomer $\left(\mathrm{K}_{\mathrm{D}} \sim 12 \mathrm{nM}\right)$, although the dimer formed by the neck domain is not compatible with two ACE2 peptidase domains interacting with two distinct RBDs in a single S trimer (Fig. S4). A possible explanation is that the neck domain mediated dimerization is not very strong and that the ACE2 peptidase domains are much more flexible than what the full-length ACE2 structure has indicated $^{18}$, particularly in the absence of $\mathrm{B}^{0} \mathrm{AT} 1$. The trimeric ACE2 615 -foldon interacted with the $\mathrm{S}$ trimer much more strongly than any of the monomeric or dimeric forms, with a $\mathrm{K}_{\mathrm{D}}$ of $1.2 \mathrm{nM}$. ACE2 ${ }_{615}$-LL-foldon with a longer linker between ACE2 and foldon showed an additional modest affinity enhancement $\left(\mathrm{K}_{\mathrm{D}} \sim 0.62 \mathrm{nM}\right)$. The two interface mutants, ACE2 615 -foldon-T27W and ACE2 615 -foldon-T27Y, bound substantially more tightly than did the trimeric wild-type ACE2, with $\mathrm{K}_{\mathrm{D}} \mathrm{S}$ of $\sim 60$ and $\sim 90 \mathrm{pM}$, respectively. While the H34W afforded a slight affinity increase, the K353Y mutation decreased affinity by more than 25-fold. Overall, these data show that our structure-guided design to increase the affinity of ACE2 to the S trimer, by trimerizing the receptor and by modifying the interface, has indeed been effective.

\section{ACE2 peptidase activity and AT1R activation}

We performed two independent assays to determine the enzymatic activity of these ACE2 constructs. First, we directly measured the peptidase activity using a synthetic peptide substrate that releases a free fluorophore upon ACE2 cleavage. In Fig. 3A, concentrations of all the proteins were normalized based on the number of active sites, and the fluorophore release was monitored continuously up to $\sim 40 \mathrm{~min}$. While all the trimeric forms showed essentially the same specific activity, the monomeric ACE2 615 and the dimeric ACE2 ${ }_{740}-\mathrm{Fc}$ had lower specific activities. The ACE2 $\mathrm{m}_{615}-\mathrm{Fc}$ was inactive due to the mutations at the active site. Thus, all these ACE2 constructs with the wildtype sequence at the active site retained their wildtype peptidase activity.

To further support this conclusion, we next tested the ability of the ACE2 constructs to block Ang II-induced activation of AT1R. In Fig. 3B, an Ang II peptide was first directly 
incubated with various ACE2 proteins and then added to HEK293 cells transfected with an AT1R expression construct. Activation of AT1R was monitored by changes in the intracellular calcium concentration. When the digestion reaction was quenched by EDTA at time 0 as a control, all the mixtures with different ACE2 proteins could efficiently activate AT1R, suggesting that nothing in our protein preparations inhibited Ang IImediated AT1R activation. In contrast, when the digestion was allowed to proceed for 40 min, all AEC2 constructs except for the inactive ACE2 $\mathrm{m}_{615}$-Fc effectively blocked AT1R activation, presumably by converting Ang II to Ang 1-7, in agreement with the peptidase activity results.

\section{Inhibition of SARS-CoV-2 infectivity in cell culture}

We used three different assays to assess the neutralization potency of the ACE2 constructs in blocking SARS-CoV-2 infection. The circulating strain during the early days of the pandemic contained a D614 residue in its S protein, but it has subsequently been replaced by an emerging strain harboring a G614 substitution ${ }^{32}$. It has been difficult to generate pseudotyped viruses with the full-length $\mathrm{S}$ from the D614 strain. We first used an MLV-based pseudovirus assay with a D614 S construct lacking 19 residues of the cytoplasmic tail, which incorporates efficiently into pseudoviruses. In Fig. 4A, the monomeric ACE2 615 showed the lowest potency with an $\mathrm{IC}_{50}$ value of $24.1 \mu \mathrm{g} / \mathrm{ml}$. The two dimeric forms, $\mathrm{ACE} 2 \mathrm{~m}_{615}-\mathrm{Fc}$ and $\mathrm{ACE} 2{ }_{740} \mathrm{Fc}$, and the trimeric mutant $\mathrm{ACE} 2{ }_{615^{-}}$ foldon-K353Y had greater potency, with $\mathrm{IC}_{50}$ values ranging from 1.2 to $6.3 \mu \mathrm{g} / \mathrm{ml}$. The two trimeric forms, ACE2 615 -foldon and ACE2 615 -LL-foldon, and the trimeric mutant ACE2 ${ }_{615}$-foldon-H34W neutralized with even greater potency and an $\mathrm{IC}_{50}$ value around $0.6 \mu \mathrm{g} / \mathrm{ml}$. The most potent inhibitors were ACE2 615 -foldon-T27W and ACE2 615 -foldonT27Y, which had $\mathrm{IC}_{50}$ values of 0.21 and $0.25 \mu \mathrm{g} / \mathrm{ml}$, respectively. Thus, the neutralization potency of these ACE2 constructs correlates strictly with their binding affinity, suggesting that the interaction between ACE2 and S is the principal determinant of neutralization of the virus pseudotyped with the CT-truncated S (D614). Neutralization by these ACE2 proteins in the HIV-based pseudovirus assay using a full-length S derived from the G614 circulating strain showed a very similar pattern with ACE2 615 the weakest and $\mathrm{ACE} 2{ }_{615}$-foldon-T27W and $\mathrm{ACE} 2{ }_{615}$-foldon-T27Y the most potent (Fig. 4B). 
Furthermore, when they were analyzed by a plaque assay with an authentic SARS-CoV2, the neutralization pattern was almost identical to that from the MLV-based assay (Fig. 4C). The $\mathrm{IC}_{50}$ values for $\mathrm{ACE} 2615$-foldon-T27W and $\mathrm{ACE} 2615$-foldon-T27Y were 0.08 and $0.14 \mu \mathrm{g} / \mathrm{ml}$, respectively. These results indicate that the engineered ACE2 constructs are very potent agents for blocking SARS-CoV-2 infection in cell culture.

\section{Discussion}

A recombinant human ACE2, named APN01, is currently under evaluation as a treatment for COVID-19 in a phase 2 clinical trial (NCT04335136), primarily based on the favorable results from a previous phase 1 safety and tolerability trial (NCT00886353) in a small number of healthy individuals ${ }^{33}$, as well as on the recent evidence that the protein blocks SARS-CoV-2 infection effectively in vitro ${ }^{26}$. APN01 is a soluble ACE2 construct expressing residues 1-740 and probably dimerizes by the neck domain ${ }^{34}$, like ACE2 ${ }_{740}$-Fc used in our study. We demonstrate here that our best trimeric ACE2 variant, ACE2 $615^{-}$ foldon-T27W, has $>200$-fold higher binding affinity for the soluble SARS-CoV-2 S trimer, and $\sim 5$-fold and $\sim 13$-fold higher neutralization potency against pseudoviruses and authentic viruses, respectively, than does $\mathrm{ACE} 2_{740}-\mathrm{Fc}$, while its peptidase activity and ability to block AT1R activation remain essentially unchanged. Using a deep mutagenesis screening approach, a recent study has identified a dimeric ACE2 variant containing multiple mutations, which led to higher affinity binding to the RBD, but also a substantial loss in the catalytic activity (4-8 fold decrease) than the parental construct with the wildtype sequence ${ }^{35}$. One of the mutations from the mutagenesis screening is $\mathrm{T} 27 \mathrm{Y}$, coinciding with our structure-based design. Our approach also distinguishes the $\mathrm{S}$ protein binding and the peptidase activity, which can be manipulated separately to maximize the therapeutic benefits of an ACE2 construct.

Although the molecular mechanism by which a soluble ACE2 blocks SARS-CoV-2 infection as a decoy receptor is obvious, its protective role against lung injury - a hallmark of severe COVID-19 cases - appears to be more complicated in humans than in animal models. ACE2 knockout mice have more severe ARDS symptoms than do wildtype mice, while ACE2 overexpression appears to be protective ${ }^{23}$. Moreover, 
administration of recombinant ACE2 reduces severity of lung injury in mice caused by respiratory syncytial virus or influenza virus ${ }^{24,25}$. In humans, rhACE2 was well tolerated with a short half-life ${ }^{33}$, but its infusion did not appear to ameliorate ARDS at least in a small number of patients ${ }^{36}$. The ongoing phase 2 clinical trial with expected 200 participants may provide much needed information regarding the therapeutic potential of recombinant ACE2 in the context of COVID-19. Structure-based modifications presented here may help augment therapeutic efficacy while suppressing adverse effects, if any.

The safety in humans of the foldon trimerization tag, derived from the bacteriophage T4 fibritin $^{30}$, has been demonstrated by vaccine trials against HIV-1 and SARS-CoV-2 in clinical settings ${ }^{37,38}$. However, a dose in $\mathrm{mg} / \mathrm{kg}$ body weight of the trimeric ACE2 proteins as a therapeutics is likely much greater than that used as a vaccine (for example, $50-250 \mu \mathrm{g}$ of foldon stabilized HIV-1 gp140 protein/injection; $\operatorname{ref}^{37}$ ). If the foldon tag induces unacceptable levels of side effects at a high dose in animals or humans, other trimerization domains, such as those in abundant human collagens ${ }^{39}$, can be considered. Further improvements of these ACE2-based therapeutic candidates include modifications to enhance protein stability by introducing additional disulfide bonds (which may reduce the catalytic activity), to modulate peptidase activity by mutating residues in or near the active site, and to increase its in vivo residence time in circulation, by strategies such as PEGylation $^{40}$.

The structure of the membrane-bound ACE2 dimer formed by the neck domain is not compatible with a binding mode of two protomers interacting with two RBDs from a single S trimer, as depicted in Fig. S4. Much stronger binding of ACE2 ${ }_{740}-\mathrm{Fc}$ to the S trimer, as well as greater neutralization potency than those of monomeric ACE2 615 and even dimeric ACE2 $\mathrm{m}_{615}$-Fc clearly indicate avidity, suggesting that the ectodomain of either ACE2 or SARS-CoV-2 S protein has much greater flexibility than the cryo-EM structures imply ${ }^{18,28,41,42}$. If the multivalency of the trimeric $S$ protein on the surface of virion and the dimeric ACE2 on the host cells indeed plays an important role during viral attachment, the binding affinity for the virus to latch on the target cells would be much stronger than the values measured using monomeric $\mathrm{ACE} 2^{41}$. It may help explain the 
unexpected transmission efficiency of SARS-CoV-2 leading to a pandemic on a surprising scale and raise the hurdle for antivirals to effectively compete with ACE2 for S binding. Trimeric ACE2 variants exerting even greater avidity than the dimeric form on the host cells may have a competitive edge over other RBD-targeting inhibitors, such as monoclonal antibodies, with similar binding affinity. 


\section{Acknowledgments:}

We thank Gary Frey for generous advice, Sarah Sterling, Richard Walsh Jr. and Shaun Rawson for technical support, and Stephen Harrison for critical reading of the manuscript. EM data were collected at the Harvard Cryo-EM Center for Structural Biology of Harvard Medical School. This work was supported by NIH grants AI147884 (to B.C.), AI147884-01A1S1 (to B.C), AI141002 (to B.C.), AI127193 (to B.C. and James Chou), a COVID19 Award by Massachusetts Consortium on Pathogen Readiness (MassCPR; to B.C.), as well as a Fast grant by Emergent Ventures (to B.C.).

\section{Author Contribution:}

B.C. and T.X. conceived the project. T.X. designed, expressed and purified ACE2 variants with help from H.P. and Y.C.. T.X. also performed binding experiments and enzymatic assays. J.L. carried out the neutralization assays using the MLV-based pseudoviruses, also designed and performed the AT1R activation experiments with contributions from S.L.. J.Z. determined the cryo-EM structures of the ACE2-S complexes. R.I.J., L.G.A.M., N.S. and A.G. carried out the neutralization assays using SARS-CoV-2. C.L.L. and M.S.S performed the neutralization assays using the HIVbased pseudoviruses. Y.C. also designed and produced the soluble S trimer. S.R.V. contributed to cell culture for protein production. B.D.Q. and M.F. created the expression constructs for the dimeric ACE2 variants. All authors analyzed the data. B.C. and T.X. wrote the manuscript with input from all other authors. 


\section{Methods}

\section{Protein expression and purification}

A synthetic gene encoding an human ACE2 fragment (residues 1-615) fused with a Cterminal 6xHis tag was generated by GenScript (Piscataway, NJ) and cloned into pCMVIRES-puro expression vector (Codex BioSolutions, Inc, Gaithersburg, MD) to create the construct $\mathrm{pACE} 2_{615}$. To construct a trimeric ACE2 variant, a DNA fragment encoding a foldon trimerization tag was inserted between the ACE2 fragment and the His tag by restriction digestion and DNA ligation to give the plasmid pACE2 615 -foldon. Site-specific mutations were introduced to the ACE2 ${ }_{615}$-foldon construct by PCR following standard protocols of site-directed mutagenesis. All the ACE2 variants were expressed in HEK 293F cells by transient transfection using Opti-MEM (Gibco-Thermo Fisher Scientific, Waltham, MA). After incubation for 4 days at $37^{\circ} \mathrm{C}$ with $5.5 \% \mathrm{CO}_{2}$, the transfected cells were harvested by centrifugation at $2,524 \mathrm{xg}$ for 30 minutes.

For the monomeric ACE2 615 protein, the cell supernatant was collected by centrifugation and loaded onto a column packed with Ni-NTA agarose beads (Qiagen, Hilden, Germany). The column was washed with a buffer containing $20 \mathrm{mM}$ Tris- $\mathrm{HCl}, \mathrm{pH} 7.5$, and $300 \mathrm{mM} \mathrm{NaCl}$. The protein was eluted using a buffer containing $100 \mathrm{mM}$ imidazole, and further purified by gel filtration chromatography on a Superdex 200 Increase 10/300 GL column (GE Healthcare, Chicago, IL)

To purify the dimeric $\mathrm{ACE} 2_{615}-\mathrm{Fc}$ and $\mathrm{ACE} 2_{740}-\mathrm{Fc}$ proteins, the cell supernatant was collected and loaded to a column packed with GammaBind Plus Sepharose beads (GE Healthcare). The column was washed with PBS. The protein was eluted using $100 \mathrm{mM}$ glycine $(\mathrm{pH} 2.5)$ and neutralized immediately with $2 \mathrm{M}$ Tris- $\mathrm{HCl}(\mathrm{pH} \mathrm{8.0)}$. The eluted protein was further purified by gel filtration chromatography on a Superdex 200 Increase 10/300 GL column.

For all the ACE2 615 -foldon variants, which were not secreted efficiently, the cell pellet was resuspended in the lysis buffer $(20 \mathrm{mM}$ Tris- $\mathrm{HCl}, \mathrm{pH} 7.5,300 \mathrm{mM} \mathrm{NaCl}, 1 \% \mathrm{NP} 40$, $20 \mathrm{mM}$ imidazole) and rocked gently for 1 hour at $4^{\circ} \mathrm{C}$, followed by spinning at 17,554 
$\mathrm{xg}$ for 30 minutes to remove cell debris. The supernatant was loaded to a column packed with Ni-NTA agarose beads (Qiagen). The column was washed with a buffer containing $20 \mathrm{mM}$ Tris- $\mathrm{HCl}, \mathrm{pH} 7.5,300 \mathrm{mM} \mathrm{NaCl}$ and $50 \mathrm{mM}$ imidazole and the protein was eluted using a buffer containing $20 \mathrm{mM}$ Tris- $\mathrm{HCl}, \mathrm{pH} 7.5,300 \mathrm{mM} \mathrm{NaCl}$ and $300 \mathrm{mM}$ imidazole. The eluted protein was further purified by gel filtration chromatography on a Superdex 200 Increase 10/300 GL column.

To produce a stabilized ectodomain of SARS-CoV-2 S trimer protein, a synthetic gene (kindly provided by Dr. Dan Barouch), encoding residues 1-1208 with the furin cleavage site (residues 682-685) replaced by a "GGSG" sequence, residues K986 and V987 substituted by prolines, and addition of a foldon trimerization tag followed by a Cterminal 6xHisTag, was cloned into the vector pCMV-IRES-puro. The expression construct was transiently transfected in HEK 293T cells using polyethylenimine (Polysciences, Inc, Warrington, PA). Protein was purified from cell supernatants using Ni-NTA resin (Qiagen), the eluted fractions containing $\mathrm{S}$ protein were pooled, concentrated, and further purified by gel filtration chromatography on a Superose 6 column (GE Healthcare).

\section{Cryo-EM sample preparation and data collection}

To prepare cryo grids, $3.5 \mu \mathrm{l}$ of the freshly prepared mixture of the soluble $\mathrm{S}$ trimer and monomeric ACE2 (1:3 molar ratio) at $\sim 1 \mathrm{mg} / \mathrm{ml}$ was applied to a 1.2/1.3 Quantifoil grid (Quantifoil Micro Tools GmbH, Germany), which had been glow discharged with a PELCO easiGlow ${ }^{\mathrm{TM}}$ Glow Discharge Cleaning system (Ted Pella, Inc., Redding, CA) for $60 \mathrm{~s}$ at $15 \mathrm{~mA}$. Grids were immediately plunge-frozen in liquid ethane using a Vitrobot Mark IV (Thermo Fisher Scientific), and excess protein was blotted away using grade 595 filter paper (Ted Pella, Inc.) with a blotting time of $4 \mathrm{~s}$, a blotting force of -12 at $4^{\circ} \mathrm{C}$ in $100 \%$ humidity. The grids were first screened for ice thickness and particle distribution using a Talos Arctica transmission electron microscope (Thermo Fisher Scientific), operated at $200 \mathrm{keV}$ and equipped with a K3 direct electron detector (Gatan), at the Harvard Cryo-EM Center for Structural Biology. For data collection, images were acquired with selected grids using a Titan Krios transmission electron microscope 
(Thermo Fisher Scientific) operated at $300 \mathrm{keV}$ with a BioQuantum GIF/K3 direct electron detector. Automated data collection was carried out using SerialEM version65 at a nominal magnification of $105,000 \times$ and the $\mathrm{K} 3$ detector in counting mode (calibrated pixel size, $0.825 \AA$ ) at a exposure rate of $\sim 14.8$ electrons per physical pixel per second. Each movie had a total accumulated electron exposure of $50 \mathrm{e} / \AA 2$ fractionated in 50 frames of $50 \mathrm{~ms}$. Datasets were acquired using a defocus range of 1.5-2.6 $\mu \mathrm{m}$.

\section{Image processing, 3D reconstructions and model building}

Drift correction for cryo-EM images was performed using MotionCor $2^{43}$, and contrast transfer function (CTF) was estimated by CTFFIND4 ${ }^{44}$ using motion-corrected sums without dose-weighting. Motion corrected sums with dose-weighting were used for all image processing. CrYOLO ${ }^{45}$ was used for particle picking, and RELION3.0.8 ${ }^{46}$ was used for 2D classification, 3D classification and refinement. A total of 407,761 particles were extracted from 4,292 images. The selected particles were subjected to 2D classification, giving a total of 261,799 good particles. A low-resolution negative-stain reconstruction of the sample was low-pass-filtered to $40 \AA$ and used as an initial model for 3D classification in $\mathrm{C} 1$ symmetry. One class containing 32,685 particles appeared to represent the free $\mathrm{S}$ trimer with no $\mathrm{ACE}$ bound was further refined in $\mathrm{C} 1$ symmetry, giving a reconstruction at $3.6 \AA$ resolution. Another major class with $\sim 49 \%$ of the selected particles showing density for ACE2 was refined in C1 symmetry and subsequently subjected to CTF refinement, Bayesian polishing and particle subtraction by masking out the ACE2-RBD density, followed by 3D classification without alignment in six classes. Whole particles were re-extracted based on the six classes from the masked local classification and refined further, revealing different stoichiometry for ACE2 binding (one ACE2 per S trimer, two ACE2 per S trimer, and three ACE2 per S trimer). Three best maps representing each type of complexes were chosen and further refined in $\mathrm{C} 1$ symmetry after CTF refinement and Bayesian polishing, leading to one reconstruction of the complex with one ACE2 bound at $3.6 \AA$ resolution from 15,964 particles; another reconstruction of the complex with two ACE2 bound at $3.7 \AA$ resolution from 13,515 particles and a third reconstruction of the complex with three ACE2 bound at $3.4 \AA$ resolution from 26,298 particles. Reported resolutions are based on the gold-standard 
Fourier shell correlation (FSC) using the 0.143 criterion. All density maps were corrected from the modulation transfer function of the $\mathrm{K} 3$ detector and then sharpened by applying a temperature factor that was estimated using post-processing in RELION. Local resolution was determined using RELION with half-reconstructions as input maps.

The initial templates for model building used the stabilized SARS-CoV-2 S ectodomain trimer structure (PDB ID: 6vyb) and ACE2 from the ACE2-B0AT1 complex structure (PDB ID: 6M17). Several rounds of manual building were performed in Coot. Iteratively, refinement was performed in both Phenix ${ }^{47}$ (real space refinement) and ISOLDE $^{48}$, and the Phenix refinement strategy included rigid body fit, minimization_global, local_grid_search, and adp, with rotamer, Ramachandran, and reference-model restraints, using $6 \mathrm{vyb}$ and $6 \mathrm{M} 17$ as the reference model. The refinement statistics are summarized in Table S1.

\section{Binding assay by bio-layer interferometry (BLI)}

Binding of ACE2 variants to the soluble $\mathrm{S}$ trimer was measured using an Octet RED384 system (ForteBio, Fremont, CA). Each ACE2 protein was diluted using the running buffer (PBS, 0.005\% Tween 20, $0.25 \mathrm{mg} / \mathrm{ml} \mathrm{BSA}$ ) and transferred to a 96-well plate. The soluble $S$ protein was immobilized to Amine Reactive $2^{\text {nd }}$ Generation (AR2G) biosensors (Fortebio), following a protocol recommended by the manufacturer. After equilibrating in the running buffer for 5 minutes, the sensors with immobilized S protein were dipped in the wells containing the ACE2 protein at various concentrations (1.852-150 nM for $\mathrm{ACE} 2{ }_{615} ; 0.926-75 \mathrm{nM}$ for $\mathrm{ACE} 2_{615}-\mathrm{Fc}$ and $\mathrm{ACE} 2{ }_{740}-\mathrm{Fc} ; 0.617-50 \mathrm{nM}$ for all the ACE2 615 -foldon variants) for 5 minutes to measure the association rate. The sensors were then dipped in the running buffer for 10 minutes to determine the dissociation rate. Control sensors with no S protein were also dipped in the ACE2 solutions and the running buffer as references. Recorded sensorgrams with background subtracted from the references were analyzed using the software Octet Data Analysis HT Version 11.1 (Fortebio). The curves for monomeric ACE2 were fit to a 1:1 binding model, while those for the oligomeric ACE2 variants were fit to a bivalent binding model. 


\section{ACE2 peptidase activity assay}

The catalytic activity of the ACE2 variants was measured by detecting a free fluorophore 7-methoxycoumarin-4-acetic acid (MCA) released from a synthetic peptide substrate, using an ACE2 activity kit (BioVision, Milpitas, CA). The ACE2 615 and ACE2 615 -foldon variants were diluted to $0.25 \mu \mathrm{g} / \mathrm{ml}$ using the assay buffer from the kit. The ACE2 $615-\mathrm{Fc}$ and $\mathrm{ACE} 2{ }_{740} \mathrm{Fc}$ proteins were diluted to 0.38 and $0.30 \mu \mathrm{g} / \mathrm{ml}$, respectively, to keep the same number of the active sites as other ACE2 variants. $50 \mu \mathrm{l}$ of diluted protein was set in the 96-well plate. Immediately before recording fluorescence signals, $50 \mu 1$ substrate diluted in the assay buffer, following a protocol recommended by the manufacturer, was added to each well. Fluorescence signals were recorded in a kinetic mode by a Flexstation 3 Multi Mode Microplate Reader (Molecular Devices, San Jose, CA). The specific activity was calculated as the amount of the released fluorophore divided by the reaction time and the amount of the ACE2 protein using the data within the initial linear phase, as described in the protocol provided by the manufacturer. To determine the initial linear phase, fluorescence signals were recorded with $1.25,0.25$ and $0.125 \mu$ g of ACE2 615 protein, respectively, reaching maximum after the substrates were completely cleaved. Data from the first 2 minutes within the linear phase with signals less than $10 \%$ of the maximum were used for the calculation. The amount of released MCA was derived from the increase of the fluorescence signal divided by the slope of the MCA standard curve.

\section{Inhibition of Ang II-induced AT1R activation}

To treat the Ang II peptide with each ACE2 variant, $2 \mu \mathrm{l}$ of ACE2 protein at $0.5 \mathrm{mg} / \mathrm{ml}$ were added to $198 \mu \mathrm{l}$ of an assay buffer (1xPBS, $40 \mathrm{mM}$ Tris-HCl, pH6.8, $20 \mu \mathrm{M} \mathrm{ZnCl}_{2}$ ) containing $65 \mu \mathrm{M}$ Ang II peptide. The reactions were incubated at $37^{\circ} \mathrm{C}$ for $40 \mathrm{~min}$, and then quenched by addition of $50 \mu \mathrm{l}$ of $0.5 \mathrm{M}$ EDTA. The final concentration of Ang II peptide was $52 \mu \mathrm{M}$. As a time 0 control, $198 \mu \mathrm{l}$ of the assay buffer containing $65 \mu \mathrm{M}$ Ang II was incubated with EDTA at $37^{\circ} \mathrm{C}$ first, followed by addition of $2 \mu \mathrm{l}$ of each ACE2 protein $(0.5 \mathrm{mg} / \mathrm{ml})$.

Changes in the intracellular calcium concentration in AT1R-expressing cells when induced by Ang II peptide were measured to monitor the activation of the receptor. 
Briefly, HEK293 cells were transfected with pCMV-AT1R-IRES-Puro gene using Lipofectamine 3000 reagent (Thermo Fisher Scientifics). Approximately 24 hours posttransfection, the cells were transferred into a 384-well black clear plate at a density of $1.2 \times 10^{4}$ cells/well in $20 \mu \mathrm{l}$ culture medium. On day 4, $20 \mu \mathrm{l}$ of $1 \mathrm{x}$ Non-Wash Calcium Dye solution (CB-80500-301, Codex BioSolutions Inc) was added into each well. The cell plate was incubated at $37^{\circ} \mathrm{C}$ in a $\mathrm{CO}_{2}$ incubator for 1 hour. The pretreated ligands (Ang II peptide) at various concentrations $(0.005-500 \mathrm{nM})$ were prepared in 1X HBSS with $20 \mathrm{mM}$ HEPES (pH7.46). Fluorescent intensity in each well was recorded on an FDSS 7000 (Hamamatsu Corporation, Bridgewater, NJ) at the rate of 1 image/sec (Ex $480 \mathrm{nM}$ and $\mathrm{Em} 540 \mathrm{nM}$ ) and the base line of each well was also recorded for 10 seconds. After the online addition of $10 \mu \mathrm{l}$ of the prepared ligands (the final concentration of 0.001-100 nM), the fluorescent intensity of each well was recorded at the rate of 1 image/sec for additional 170 seconds.

\section{MLV-based pseudovirus assay}

Murine Leukemia Virus (MLV) particles (all plasmids of the MLV components were kindly provided by Dr. Gary Whittaker at Cornell University and Drs. Catherine Chen and Wei Zheng at National Center for Advancing Translational Sciences, National Institutes of Health), pseudotyped with a SARS-CoV-2 S protein construct, were generated in HEK 293T cells, following a protocol described previously for SARS$\mathrm{CoV}^{49,50}$. To enhance incorporation, $\mathrm{C}$-terminal 19 residues in the cytoplasmic tail of the SARS-CoV-2 S protein containing D614 were deleted. To prepare for infection, $7.5 \times 10^{3}$ of Expi-293F cells, stably transfected with a full-length human ACE2 expression construct, in $15 \mu \mathrm{l}$ culture medium were plated into a 384-well white-clear plate coated with poly-D-Lysine to enhance cell attachment. On day 2, $12.5 \mu$ l of SARS-CoV-2 MLV pseudoviruses were mixed with $5 \mu$ of each ACE2 variant at different concentrations $(0.001-300 \mu \mathrm{g} / \mathrm{ml})$ and incubated at $37^{\circ} \mathrm{C}$ for $1 \mathrm{hr}$. After the medium in each well containing the cells was removed, $17.5 \mu \mathrm{l}$ of each ACE2-virus mixture were added. The plate was centrifuged at $54 \mathrm{xg}$ for $15 \mathrm{~min}$ at $4^{\circ} \mathrm{C}$ and additional $7.5 \mu \mathrm{l}$ of culture medium were then added. The total final volume in each well was $25 \mu l$. The cells were then 
incubated at $37^{\circ} \mathrm{C}$ for $42 \mathrm{hr}$. Luciferase activities were measured with Firefly Luciferase Assay Kit (CB-80552-010, Codex BioSolutions Inc). IC $_{50}$ values were calculated based on curve fitting in GraphPad Prism.

\section{HIV-based pseudovirus assay}

Neutralization of HIV-based pseudovirus containing a full-length SARS-CoV-2 S protein was measured using a single-round infection assay in HEK 293T/ACE2 target cells. Pseudotyped virus particles were produced in 293T/17 cells (ATCC) by co-transfection of a plasmid encoding codon-optimized SARS-CoV-2 full-length S containing G614, a packaging plasmid pCMV $\triangle \mathrm{R} 8.2$ expressing HIV gag and pol, and a luciferase reporter plasmid pHR' CMV-Luc. All plasmids were kindly provided by Dr. Barney Graham (NIH, Vaccine Research Center). The 293T cell line stably overexpressing the human ACE2 protein was created by the Farzan group at Scripps Research Institute. For neutralization assays, serial dilutions of the ACE2 constructs were performed in duplicate followed by addition of pseudoviruses. Plates were incubated for 1 hour at $37^{\circ} \mathrm{C}$ followed by addition of $293 \mathrm{~T} / \mathrm{ACE} 2$ target cells ( $1 \times 10^{4} /$ well). Wells containing cells and pseudoviruses without ACE2 proteins or cells alone were positive and negative infection controls, respectively. Assays were harvested on day 3 using BrightGlo luciferase reagent (Promega, Madison, WI) and luminescence detected with a Victor luminometer (PerkinElmer, Waltham, MA). $\mathrm{IC}_{50}$ values are reported as the ACE2 protein concentration that inhibited 50\% virus infection. All neutralization experiments were repeated twice with similar results.

\section{Neutralization of authentic SARS-CoV-2}

ACE2 variants were serially diluted in Dulbecco's Phosphate Buffered Saline $(\mathrm{DPBS})\left(\mathrm{Gibco}^{\mathrm{TM}}\right)$ using half-log dilutions starting at 31,579 $\mathrm{ng} / \mathrm{ml}$. Dilutions were prepared in triplicate for each protein. Each dilution was incubated at $37^{\circ} \mathrm{C}$ in $5 \% \mathrm{CO}_{2}$ for 1 hour with 1,000 plaque forming units/ml (PFU/ml) of SARS-CoV-2 (isolate USA WA1/2020). Controls included Dulbecco's Modified Eagle Medium (DMEM) (GibcoThermo Fisher Scientific) containing 2\% fetal bovine serum (Gibco-Thermo Fisher Scientific) and antibiotic-antimycotic (Gibco-Thermo Fisher Scientific) only as a 
negative control, 1000 PFU/ml SARS-CoV-2 (USA-WA1/2020) incubated with DPBS, and $1000 \mathrm{PFU} / \mathrm{ml}$ SARS-CoV-2 incubated with DMEM. $200 \mu \mathrm{l}$ of each dilution or control were added to confluent monolayers of NR-596 Vero E6 cells in triplicate and incubated for 1 hour at $37^{\circ} \mathrm{C}$ and $5 \% \mathrm{CO}_{2}$. The plates were gently rocked every 5-10 minutes to prevent monolayer drying. The monolayers were then overlaid with a $1: 1$ mixture of $2.5 \%$ Avicel ${ }^{\circledR}$ RC-591 microcrystalline cellulose and carboxymethylcellulose sodium (DuPont Nutrition \& Biosciences, Wilmington, DE) and 2X Modified Eagle Medium (Temin's modification, Gibco-Thermo Fisher Scientific) supplemented with $2 \mathrm{X}$ antibiotic - antimycotic, 2X GlutaMAX (Gibco-Thermo Fisher Scientific) and 10\% fetal bovine serum. Plates were incubated at $37^{\circ} \mathrm{C}$ and $5 \% \mathrm{CO}_{2}$ for 2 days. The monolayers were fixed with $10 \%$ neutral buffered formalin and stained with $0.2 \%$ aqueous Gentian Violet (RICCA Chemicals, Arlington, TX) in 10\% neutral buffered formalin for $30 \mathrm{~min}$, followed by rinsing and plaque counting. The half maximal inhibitory concentrations ( $\left.\mathrm{IC}_{50}\right)$ were calculated using GraphPad Prism 8. 


\section{References:}

1. Duan, K. et al. Effectiveness of convalescent plasma therapy in severe COVID19 patients. Proc Natl Acad Sci U S A 117, 9490-9496 (2020).

2. Bloch, E.M. et al. Deployment of convalescent plasma for the prevention and treatment of COVID-19. J Clin Invest 130, 2757-2765 (2020).

3. Shen, C. et al. Treatment of 5 Critically Ill Patients With COVID-19 With Convalescent Plasma. JAMA (2020).

4. Wec, A.Z. et al. Broad neutralization of SARS-related viruses by human monoclonal antibodies. Science (2020).

5. Shi, R. et al. A human neutralizing antibody targets the receptor binding site of SARS-CoV-2. Nature (2020).

6. Chi, X. et al. A neutralizing human antibody binds to the N-terminal domain of the Spike protein of SARS-CoV-2. Science (2020).

7. $\mathrm{Wu}, \mathrm{Y}$. et al. A noncompeting pair of human neutralizing antibodies block COVID-19 virus binding to its receptor ACE2. Science 368, 1274-1278 (2020).

8. Xia, S. et al. Inhibition of SARS-CoV-2 (previously 2019-nCoV) infection by a highly potent pan-coronavirus fusion inhibitor targeting its spike protein that harbors a high capacity to mediate membrane fusion. Cell Res 30, 343355 (2020).

9. Xia, S. et al. Fusion mechanism of 2019-nCoV and fusion inhibitors targeting HR1 domain in spike protein. Cell Mol Immunol 17, 765-767 (2020).

10. Sanders, J.M., Monogue, M.L., Jodlowski, T.Z. \& Cutrell, J.B. Pharmacologic Treatments for Coronavirus Disease 2019 (COVID-19): A Review. JAMA (2020).

11. Wu, R. et al. An Update on Current Therapeutic Drugs Treating COVID-19. Curr Pharmacol Rep, 1-15 (2020).

12. Boulware, D.R. et al. A Randomized Trial of Hydroxychloroquine as Postexposure Prophylaxis for Covid-19. N Engl J Med 383, 517-525 (2020).

13. Jin, Z. et al. Structure of M(pro) from SARS-CoV-2 and discovery of its inhibitors. Nature 582, 289-293 (2020).

14. Gao, Y. et al. Structure of the RNA-dependent RNA polymerase from COVID19 virus. Science 368, 779-782 (2020).

15. Polak, S.B., Van Gool, I.C., Cohen, D., von der Thusen, J.H. \& van Paassen, J. A systematic review of pathological findings in COVID-19: a pathophysiological timeline and possible mechanisms of disease progression. Mod Pathol (2020).

16. Zhou, P. et al. A pneumonia outbreak associated with a new coronavirus of probable bat origin. Nature (2020).

17. Hoffmann, M. et al. SARS-CoV-2 Cell Entry Depends on ACE2 and TMPRSS2 and Is Blocked by a Clinically Proven Protease Inhibitor. Cell (2020).

18. Yan, R. et al. Structural basis for the recognition of SARS-CoV-2 by full-length human ACE2. Science 367, 1444-1448 (2020).

19. Tikellis, C., Bernardi, S. \& Burns, W.C. Angiotensin-converting enzyme 2 is a key modulator of the renin-angiotensin system in cardiovascular and renal disease. Curr Opin Nephrol Hypertens 20, 62-8 (2011). 
20. Clarke, N.E. \& Turner, A.J. Angiotensin-converting enzyme 2: the first decade. Int J Hypertens 2012, 307315 (2012).

21. Dasgupta, C. \& Zhang, L. Angiotensin II receptors and drug discovery in cardiovascular disease. Drug Discov Today 16, 22-34 (2011).

22. Hemnes, A.R. et al. A potential therapeutic role for angiotensin-converting enzyme 2 in human pulmonary arterial hypertension. Eur Respir J 51(2018).

23. Imai, Y. et al. Angiotensin-converting enzyme 2 protects from severe acute lung failure. Nature 436, 112-6 (2005).

24. Gu, H. et al. Angiotensin-converting enzyme 2 inhibits lung injury induced by respiratory syncytial virus. Sci Rep 6, 19840 (2016).

25. Zou, Z. et al. Angiotensin-converting enzyme 2 protects from lethal avian influenza A H5N1 infections. Nat Commun 5, 3594 (2014).

26. Monteil, V. et al. Inhibition of SARS-CoV-2 Infections in Engineered Human Tissues Using Clinical-Grade Soluble Human ACE2. Cell 181, 905-913 e7 (2020).

27. Kirchdoerfer, R.N. et al. Stabilized coronavirus spikes are resistant to conformational changes induced by receptor recognition or proteolysis. Sci Rep 8, 15701 (2018).

28. Cai, Y. et al. Distinct conformational states of SARS-CoV-2 spike protein. Science (2020).

29. Zhou, T. et al. A pH-dependent switch mediates conformational masking of SARS-CoV-2 spike. bioRxiv (2020).

30. Meier, S., Guthe, S., Kiefhaber, T. \& Grzesiek, S. Foldon, the natural trimerization domain of T4 fibritin, dissociates into a monomeric A-state form containing a stable beta-hairpin: atomic details of trimer dissociation and local beta-hairpin stability from residual dipolar couplings. J Mol Biol 344, 1051-69 (2004).

31. Lan, J. et al. Structure of the SARS-CoV-2 spike receptor-binding domain bound to the ACE2 receptor. Nature (2020).

32. Korber, B. et al. Tracking Changes in SARS-CoV-2 Spike: Evidence that D614G Increases Infectivity of the COVID-19 Virus. Cell 182, 812-827 e19 (2020).

33. Haschke, M. et al. Pharmacokinetics and pharmacodynamics of recombinant human angiotensin-converting enzyme 2 in healthy human subjects. Clin Pharmacokinet 52, 783-92 (2013).

34. Poglitsch, M. et al. Recombinant Expression and Characterization of Human and Murine ACE2: Species-Specific Activation of the Alternative ReninAngiotensin-System. Int J Hypertens 2012, 428950 (2012).

35. Chan, K.K. et al. Engineering human ACE2 to optimize binding to the spike protein of SARS coronavirus 2. Science 369, 1261-1265 (2020).

36. Khan, A. et al. A pilot clinical trial of recombinant human angiotensinconverting enzyme 2 in acute respiratory distress syndrome. Crit Care 21, 234 (2017).

37. Barouch, D.H. et al. Evaluation of a mosaic HIV-1 vaccine in a multicentre, randomised, double-blind, placebo-controlled, phase $1 / 2 \mathrm{a}$ clinical trial (APPROACH) and in rhesus monkeys (NHP 13-19). Lancet 392, 232-243 (2018). 
38. Mulligan, M.J. et al. Phase 1/2 study of COVID-19 RNA vaccine BNT162b1 in adults. Nature (2020).

39. Sharma, U. et al. Structural basis of homo- and heterotrimerization of collagen I. Nat Commun 8, 14671 (2017).

40. Jevsevar, S., Kunstelj, M. \& Porekar, V.G. PEGylation of therapeutic proteins. Biotechnol J 5, 113-28 (2010).

41. Wrapp, D. et al. Cryo-EM structure of the 2019-nCoV spike in the prefusion conformation. Science (2020).

42. Walls, A.C. et al. Structure, function and antigenicity of the SARS-CoV-2 spike glycoprotein. Cell, DOI: 10.1016/j.cell.2020.02.058 (2020).

43. Zheng, S.Q. et al. MotionCor2: anisotropic correction of beam-induced motion for improved cryo-electron microscopy. Nat Methods 14, 331-332 (2017).

44. Rohou, A. \& Grigorieff, N. CTFFIND4: Fast and accurate defocus estimation from electron micrographs. J Struct Biol 192, 216-21 (2015).

45. Wagner, T. et al. SPHIRE-crYOLO is a fast and accurate fully automated particle picker for cryo-EM. Commun Biol 2, 218 (2019).

46. Scheres, S.H. RELION: implementation of a Bayesian approach to cryo-EM structure determination. J Struct Biol 180, 519-30 (2012).

47. Adams, P.D. et al. PHENIX: a comprehensive Python-based system for macromolecular structure solution. Acta crystallographica. Section D, Biological crystallography 66, 213-21 (2010).

48. Croll, T.I. ISOLDE: a physically realistic environment for model building into low-resolution electron-density maps. Acta Crystallogr D Struct Biol 74, 519530 (2018).

49. Millet, J.K. \& Whittaker, G.R. Murine Leukemia Virus (MLV)-based Coronavirus Spike-pseudotyped Particle Production and Infection. Bio Protoc 6(2016).

50. Chen, C.Z. et al. Identifying SARS-CoV-2 entry inhibitors through drug repurposing screens of SARS-S and MERS-S pseudotyped particles. bioRxiv (2020). 


\section{Figures and Figure Legends}

A

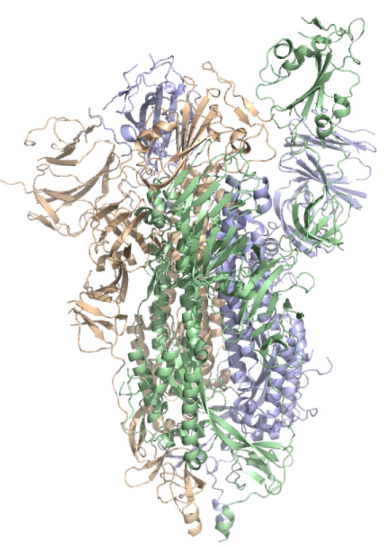

C

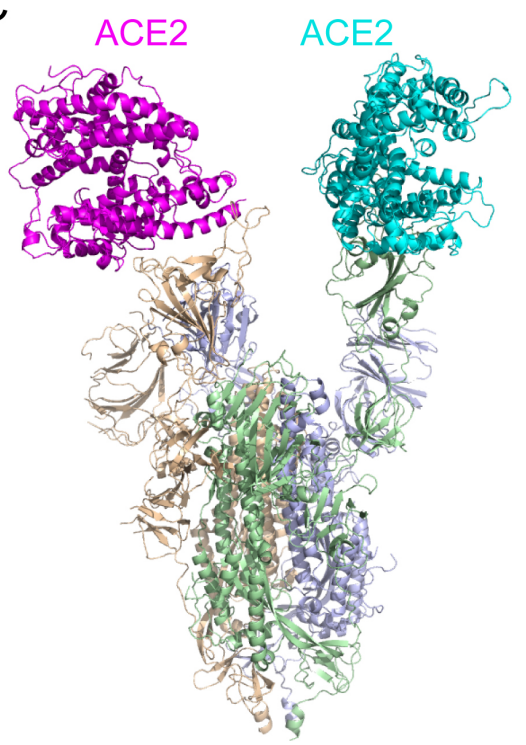

B
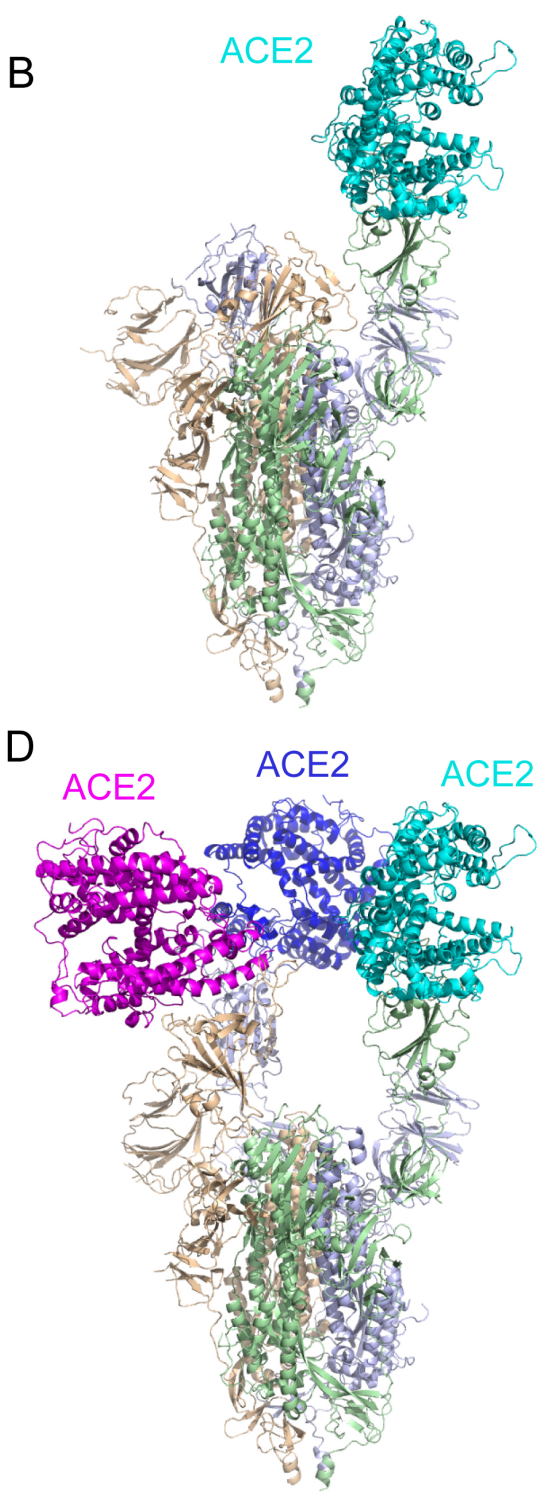

Figure 1. Cryo-EM structures of the ACE2-soluble $S$ trimer complexes. Four distinct classes were identified and refined from a sample prepared by mixing a monomeric ACE2 and the stabilized soluble SARS-CoV-2 trimer. (A) The structure of the S trimer without ACE2 in a conformation with one RBD up was modeled based on a $3.6 \AA$ density map. Three protomers are colored in green, blue and wheat, respectively. (B)-(D) The

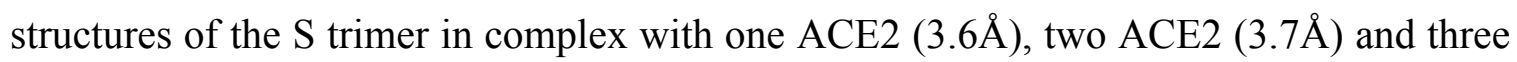

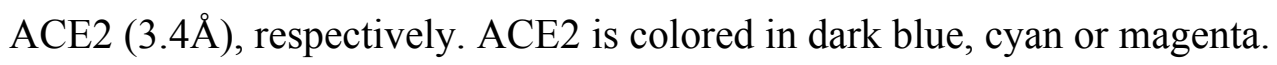


A
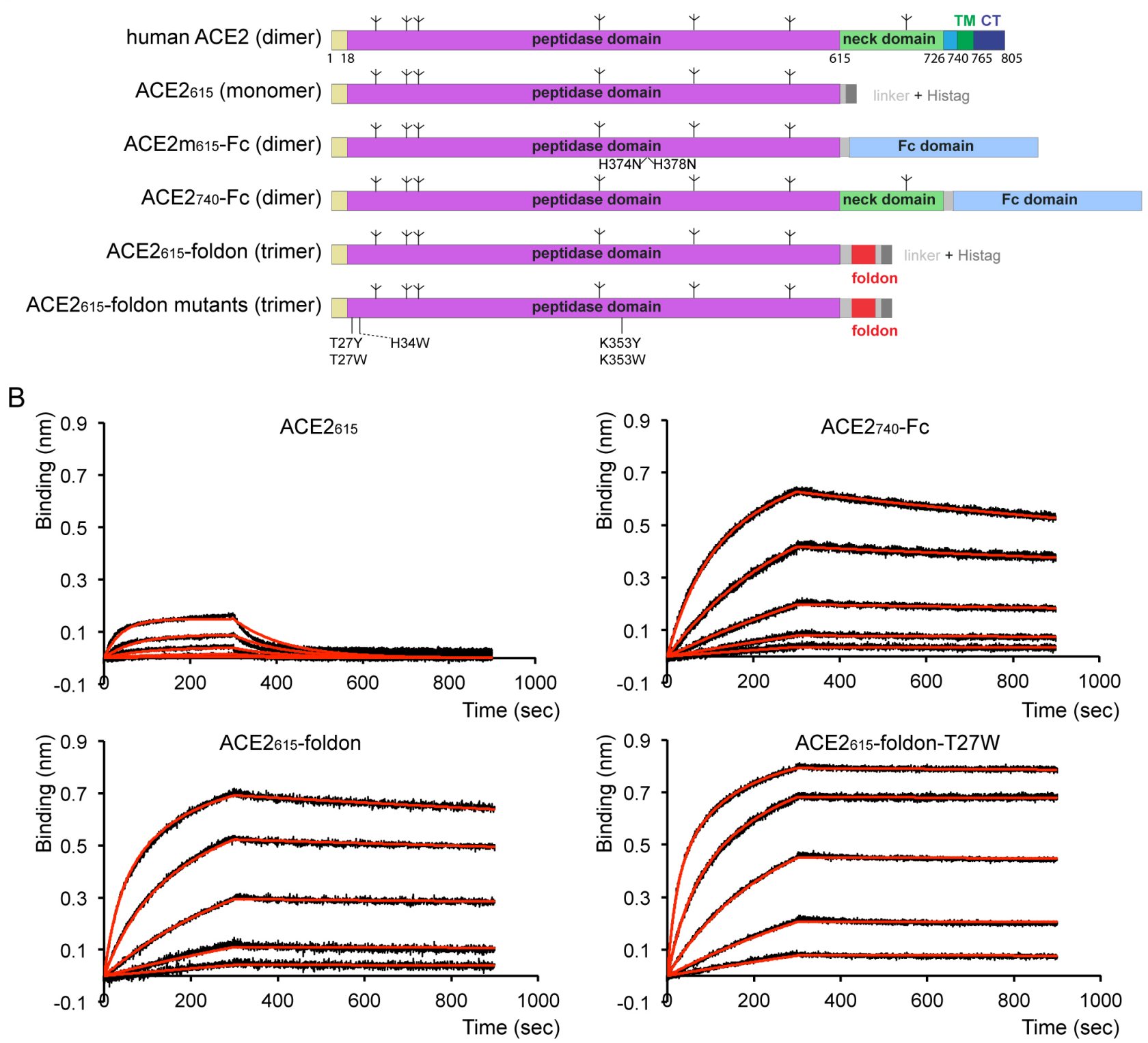

C

\begin{tabular}{|c|c|c|c|c|c|c|c|c|c|}
\hline Construct & ACE2615 & ACE2m615-Fc & ACE2740-FC & ACE2615-foldon & $\begin{array}{l}\text { ACE2615-LL } \\
\text {-foldon }\end{array}$ & $\begin{array}{c}\text { ACE2615-foldon } \\
-T 27 Y\end{array}$ & $\begin{array}{c}\text { ACE2615-foldon } \\
\text {-T27W }\end{array}$ & $\begin{array}{c}\text { ACE2615-foldon } \\
-\mathrm{H} 34 \mathrm{~W}\end{array}$ & $\begin{array}{c}\text { ACE2615-foldon } \\
-\mathrm{K} 353 \mathrm{Y}\end{array}$ \\
\hline $\mathrm{KD}(\mathrm{nM})$ & $76.8 \pm 0.8$ & $22.3 \pm 2.2$ & $12.4 \pm 0.6$ & $1.15 \pm 0.05$ & $0.62 \pm 0.03$ & $0.09 \pm 0.01$ & $0.06 \pm 0.01$ & $0.37 \pm 0.01$ & $32.3 \pm 1.8$ \\
\hline
\end{tabular}

Figure 2. Design and characterization of ACE2 variants. (A) Schematic representation of the full-length human ACE2. Various segments include: catalytic peptidase domain, neck domain; TM, transmembrane anchor; CT, cytoplasmic tail; and tree-like symbols for glycans. Expression constructs of various forms of ACE2 used in this study: ACE2 615 , an inactive peptidase domain with mutations at the active site (H374N and H378N) fused with a C-terminal histag via a flexible linker; $\mathrm{ACE}_{2} \mathrm{~m}_{615} \mathrm{-Fc}$, the peptidase domain fused 
to a Fc fragment of an immunoglobulin $\mathrm{G}$ at the C-terminus; ACE2 ${ }_{740}-\mathrm{Fc}$, the peptidase and neck domains fused to a Fc fragment at the C-terminus; ACE2 615 -foldon, the peptidase domain fused to a trimerization tag- foldon, followed by a C-terminal histag; ACE2 615 -foldon mutants, single mutations (T27Y, T27W, H34W, K353Y and K353W) were introduced in the context of ACE2 615 -foldon construct. (B) Binding of ACE2 variants to the stabilized soluble $\mathrm{S}$ trimer by bio-layer interferometry (BLI). The S protein was immobilized to AR2G biosensors, which were dipped into the wells containing ACE2 at various concentrations (1.852-150 nM for ACE2 $615,0.926-75 \mathrm{nM}$ for ACE2 $740^{-}$ Fc and $0.617-50 \mathrm{nM}$ for all the ACE2 615 -foldon variants). Binding kinetics was evaluated using a 1:1 Langmuir binding model for the monomeric ACE2 615 and a bivalent model for all other oligomeric ACE2. The sensorgrams are in black and the fits in red. All experiments were repeated at least twice with essentially identical results. (C) Summary of binding constants derived from the BLI experiments. 
A

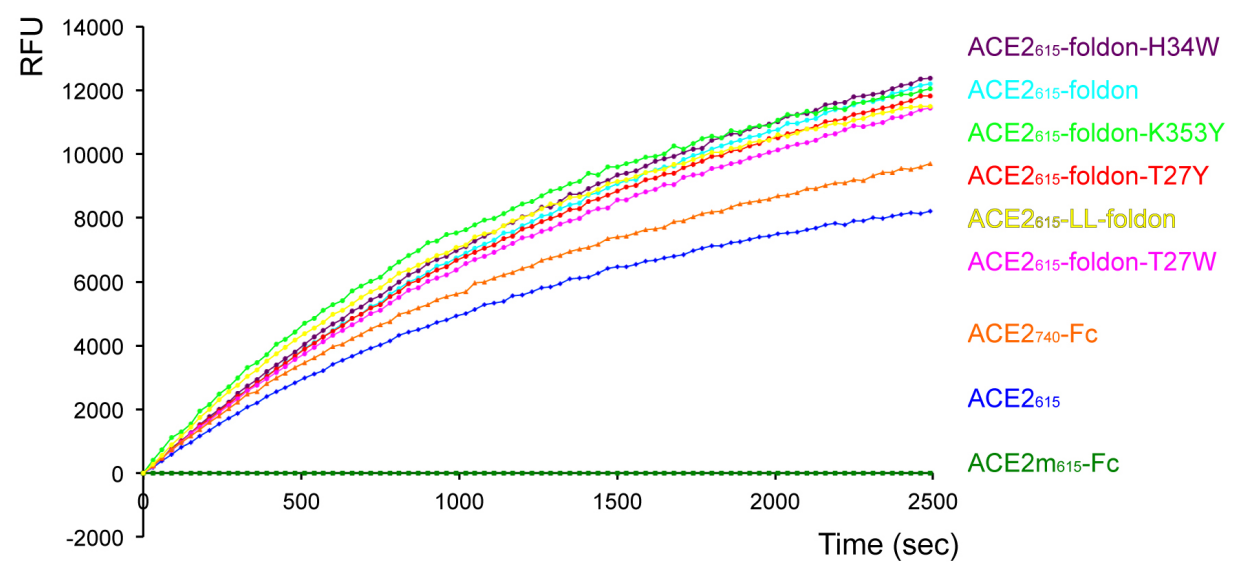

\begin{tabular}{ccccccccc}
\hline Construct & ACE2615 & ACE2m615-Fc ACE2740-FC & ACE2615-foldon & $\begin{array}{c}\text { ACE2615-LL } \\
\text {-foldon }\end{array}$ & $\begin{array}{c}\text { ACE2615-foldon } \\
\text {-T27Y }\end{array}$ & $\begin{array}{c}\text { ACE2615-foldon } \\
\text {-T27W }\end{array}$ & $\begin{array}{c}\text { ACE2615-foldon ACE2615-foldon } \\
\text {-H34W }\end{array}$ & -K353Y \\
\hline $\begin{array}{c}\text { Specific Activity } \\
\text { (mU/ng) }\end{array}$ & 4.5 & 0.0 & 3.6 & 5.6 & 6.5 & 5.6 & 5.4 & 5.7 \\
\hline
\end{tabular}

B

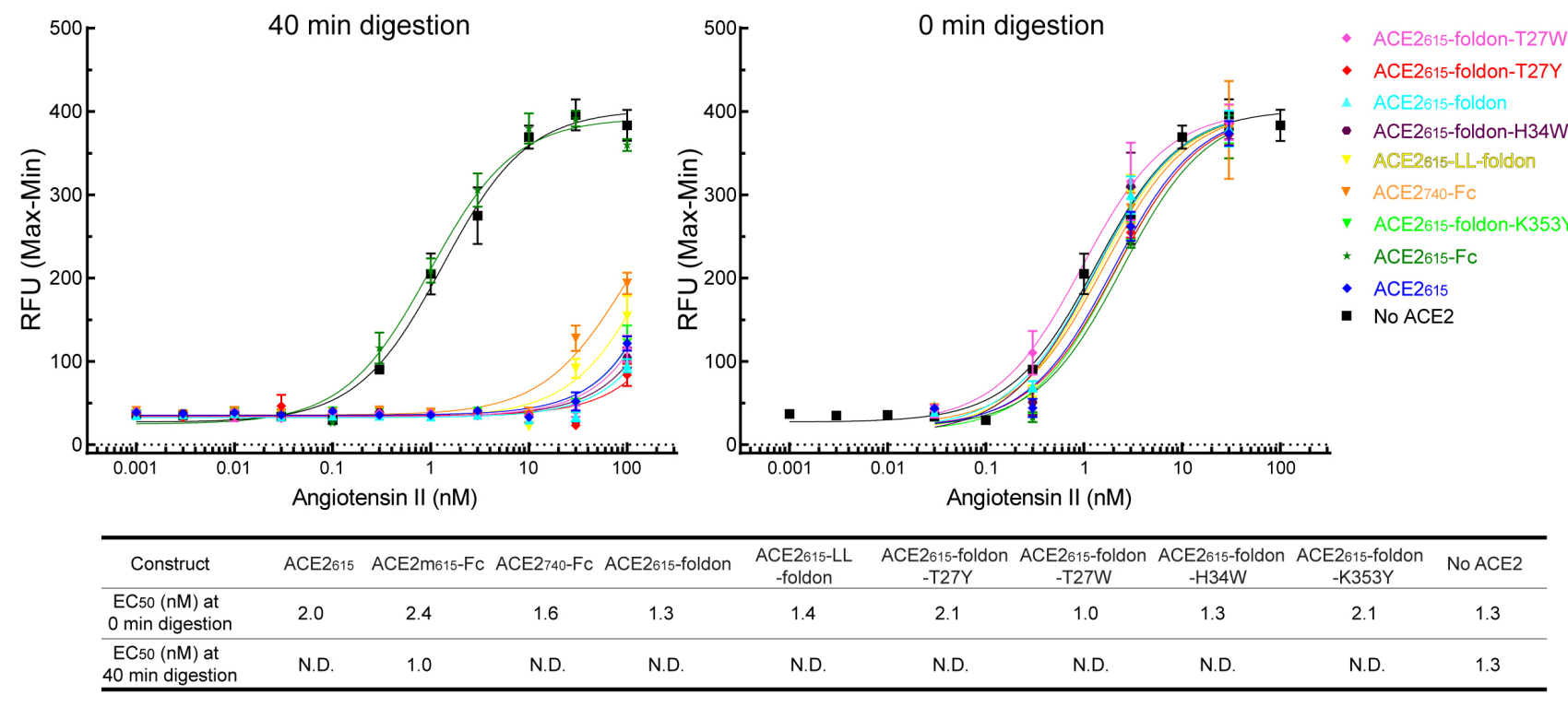

Figure 3. ACE2 peptidase activity and negative regulation of Ang II receptor type 1

activation. (A) Peptidase activity of the ACE2 variants were measured by detecting free fluorophore released from a synthetic peptide substrate. A time-course experiment was performed and specific activity was calculated. The experiment has been repeated twice with similar results. (B) Ang II peptide was treated with various ACE2 variants before adding to the cells expressing Ang II receptor type 1 (AT1R) at different concentrations. AT1R activation was quantified by changes in the intracellular calcium concentration. Samples quenched at time 0 were used as controls. The y-axis is Ratio (Max-Min) (Peak 
bioRxiv preprint doi: https://doi.org/10.1101/2020.09.18.301952; this version posted September 18, 2020. The copyright holder for this preprint (which was not certified by peer review) is the author/funder. All rights reserved. No reuse allowed without permission.

fluorescent intensity - baseline fluorescent intensity). The $\mathrm{EC}_{50}$ values were also summarized. 
bioRxiv preprint doi: https://doi.org/10.1101/2020.09.18.301952; this version posted September 18, 2020. The copyright holder for this preprint (which was not certified by peer review) is the author/funder. All rights reserved. No reuse allowed without permission.

A MLV backbone/strain D614/S with CT deletion/HEK293-ACE2 cells

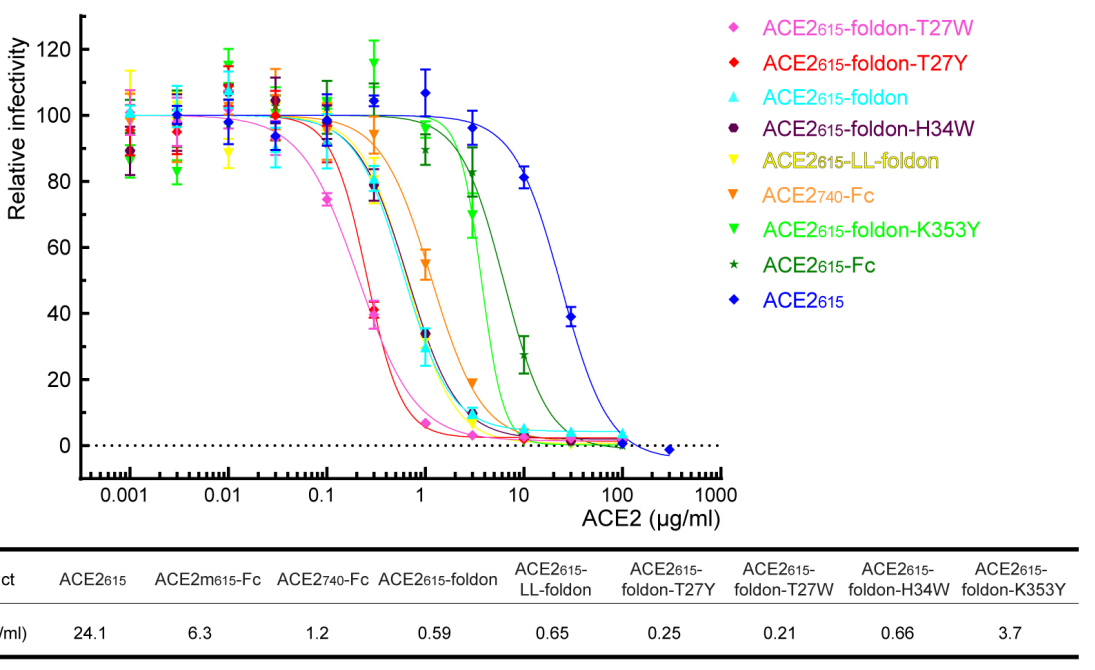

B

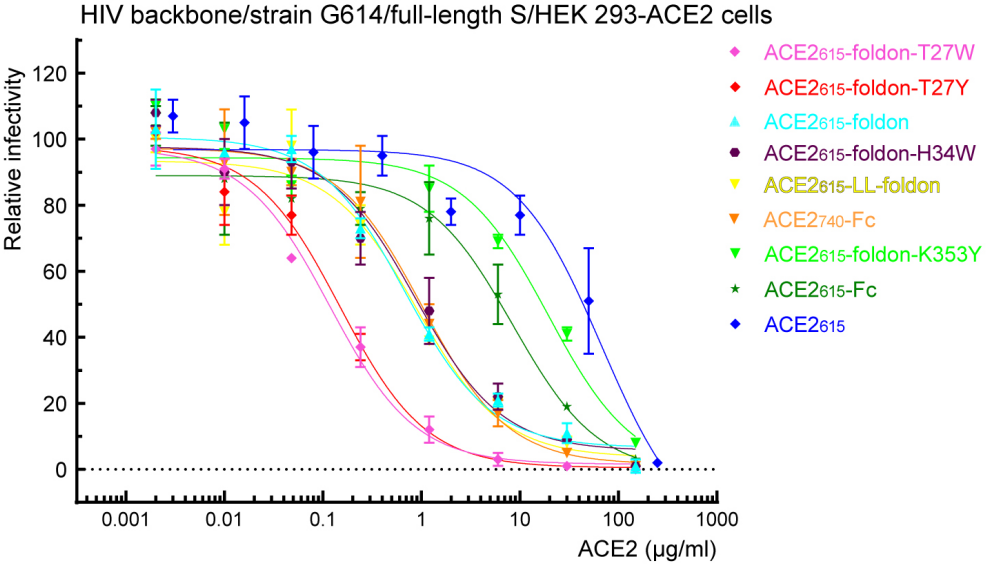

\begin{tabular}{|c|c|c|c|c|c|c|c|c|c|}
\hline Construct & ACE2615 & ACE2mb15-Fc & ACE2740-Fc & ACE2615-foldon & $\begin{array}{l}\text { ACE2615- } \\
\text { LL-foldon }\end{array}$ & $\begin{array}{l}\text { ACE2615- } \\
\text { foldon-T27Y }\end{array}$ & $\begin{array}{l}\text { ACE2615- } \\
\text { foldon-T27W }\end{array}$ & $\begin{array}{c}\text { ACE2615- } \\
\text { foldon-H34W }\end{array}$ & $\begin{array}{c}\text { ACE2615- } \\
\text { foldon-K353Y }\end{array}$ \\
\hline $\mid \mathrm{C}_{50}(\mu \mathrm{g} / \mathrm{ml})$ & 67.7 & 8.4 & 1.0 & 0.69 & 0.90 & 0.15 & 0.12 & 0.88 & 19.5 \\
\hline
\end{tabular}

C

Authentic SARS-CoV-2 (isolate USA-WA1/2020)/Nero E6 cells

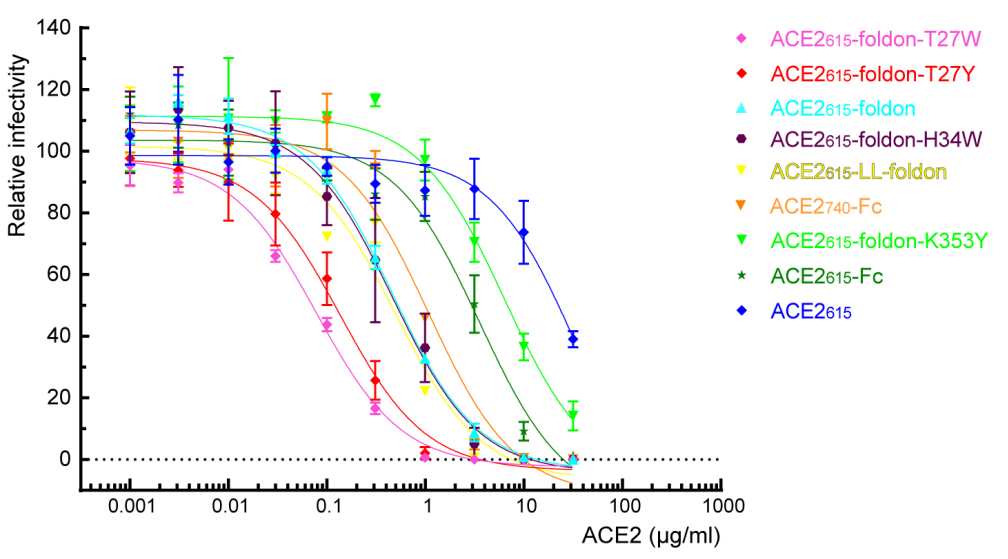

\begin{tabular}{cccccccccc}
\hline Construct & ACE2615 & ACE2m615-Fc & ACE2740-Fc & ACE2615-foldon & $\begin{array}{c}\text { ACE2615- } \\
\text { LL-foldon }\end{array}$ & $\begin{array}{c}\text { ACE2615- } \\
\text { foldon-T27Y }\end{array}$ & $\begin{array}{c}\text { ACE2615- } \\
\text { foldon-T27W }\end{array}$ & $\begin{array}{c}\text { ACE2615- } \\
\text { foldon-H34W }\end{array}$ & $\begin{array}{c}\text { ACE2615- } \\
\text { foldon-K353Y }\end{array}$ \\
\hline $\mathrm{IC} 50(\mu \mathrm{g} / \mathrm{ml})$ & N.D. & 3.5 & 1.1 & 0.46 & 0.49 & 0.14 & 0.08 & 0.46 & 6.3 \\
\hline
\end{tabular} 
Figure 4. Inhibition of SARS-CoV-2 pseudoviruses and authentic viruses by ACE2 variants. (A) Serial dilutions of each ACE2 variant were tested for inhibition against an MLV-based pseudotyped virus using a SARS-CoV-2 S construct containing D614 and a CT deletion in a single-round infection of HEK293-ACE2 cells. IC $_{50}$ values were derived from curve fitting. The experiments were repeated three times with similar results. (B) ACE2 variants were tested for inhibition against an HIV-based pseudotyped virus using a full-length SARS-CoV-2 S construct containing G614 in a single-round infection of HEK293-ACE2 cells. IC 50 values were derived from curve fitting. The experiments were repeated twice with similar results. (C) Serial dilutions of each ACE2 variant were tested for inhibition against an authentic SARS-CoV-2 S virus (isolate USA-WA1/2020) infecting Vero E6 cells. $\mathrm{IC}_{50}$ values were derived from curve fitting. The experiments were repeated three times with similar results. 